wide a general knowledge of horses, but the proof-reading and transliterations are less good than they should be. Use is made, also, of several expressions confusing in English: 'diluvial' (for 'the diluvial age') is obscure in this context, and the alteration of the book's title itself surely does not exactly render the author's intention.

IVOR MONTAGU

Deer of the World, by G. Kenneth Whitehead. Constable, $£ 5$.

The author has collected together a considerable amount of information on the Cervidae from old books, long out of print, and from more recent publications, and presented this very successfully within the space of less than 200 pages. Unfortunately, in the virtual absence of references within the text, the reader will have difficulty with certain topics in determining where the old ends and the new begins. Geographical ranges appear generally to follow earlier rather than present distributions. Current ranges of deer such as the Chinese sika, swamp deer, and the fallow deer in Turkey occupy only a fraction of the areas shown on the maps. In fact, the Turkish fallow deer presently occurs outside the range depicted. Geographical limits of certain South American deer, on the other hand, are not wide enough. Both the marsh and pampas deer range well within Bolivia, the former actually reaching southern Peru. There is an extremely interesting review of the economic uses of deer, but the chapter on antlers might have provided greater interest for the general reader if it had included some data from recent behavioural studies on the use and function of antlers, at the expense of material on natural and induced abnormalities in antler growth.

There are some excellent plates, including a unique photograph of the shou (now possibly extinct). If Riddel's painting of the hangul is a reliable indicator, however, the plates of artists' impressions of deer probably bear little relationship to the living animals. The bibliography is largely confined to books and the more substantial monographs on Cervidae; one or two publications within this category have, rather surprisingly, been omitted.

COLIN HOLLOWAY

\title{
The Leaping Hare, by George Ewart Evans and David Thom- son. Faber, £3.50.
}

The title refers not only to the animal's physical leaping and springing but also to its association, in many languages and mythologies, with the springing up of life, the intuitive leaping mind and to spiritual and religious connotations.

Although sometimes gregarious, hares tend to be elusive, remote and solitary. They have been linked with mystery and magic, witchcraft and trickery, and, like the phoenix, have been a symbol of regeneration in a divine fire that cleanses and renews. In Chinese mythology "the hare in the moon' was a resurrection symbol; in Indian legend it was a sacrificial animal, while it also figured in the folklore of the North American Indians and in Greek and Roman mythology. The authors, with their wide knowledge of rural beliefs of 50-100 years ago, have found many parallels in Britain. The reluctance of some countrymen to eat the hare, the taboo on its name among some Scottish fishermen, the hare-witch stories of Wales and Ireland, all support the belief that 'there is some sort of enchantment in the hare'.

The authors place great reliance on transcripts from tape-recordings and talks with countrymen, sometimes quoted to excess, but they have read widely and industriously and sought information and advice from many 